\title{
ESTEREOTIPOS FEMENINOS Y MÁSCARAS DE LA RETÓRICA: MES APPRENTISSAGES DE COLETTE
}

\section{FEMALE STEREOTYPES AND RETHORIC MASKS: MES APPRENTISSAGES DE COLETTE}

\section{Vicenta Hernández Álvarez}

\section{RESUMEN:}

Sidonie-Gabrielle Colette, también conocida como Colette, fue una reconocida autora francesa. En 1936 publicó Mes Apprentissages, un libro de corte autobiográfico, en el que Colette describe su relación con Willy; en la obra se refleja a una mujer movida por sus emociones. Este artículo pretende sacar a la luz los diferentes aspectos de la personalidad de su autora a través de las páginas de sus propias obras.

\section{Palabras claves:}

Colette, Mes apprentissages, mujer.

\section{Abstract:}

Sidonie-Gabrielle Colette, also known as Colette, was a famous French authoress. In 1936 she published Mes Apprentissages, an autobiographical book, in which Colette describes her relationship with Willy; the work reflects a woman who acts on her emotions. This article aims to bring to light the different aspects of the personality of the writer throughout the pages of her own works.

\section{KEY WORD:}

Colette, Mes apprentissages, woman. 
Colette tiene 63 años cuando en 1936 publica Mes Apprentissages. Ya hace años que es una autora de éxito en Francia, y que el mito de Colette está en pie. El título de Mes Apprentissages puede despistar, su carácter autobiográfico puede dar a entender que se trata de una obra de los comienzos, de una preparación a la vida y a la escritura. Sin embargo, se trata de una obra de madurez, de una obra de recuerdos y de reestructuración del pasado, de un ejercicio de introspección y de lucidez. Las máscaras han sido recurrentes en los textos de Colette, más aún en aquellos textos que podrían haber pasado por autobiográficos si la autora no estableciera explícitamente las distancias con respecto a su experiencia, si no rechazara verbalmente la identificación. Colette, la célebre autora des Claudine, no es Claudine, sin embargo, las semejanzas abundan; pero si tras las diferentes Claudine se esconden fragmentos de una cierta Colette, Mes Apprentissages afirma, treinta años más tarde, que por fin va a desvelarse aquello que no se dijo, que Claudine no dijo, y así, de algún modo, se ratifica a posteriori y desde la distancia el verdadero carácter autobiográfico de la serie de Claudine, antes tantas veces desmentido. Aparentemente, una mujer de 63 años, ya no tendría miedo de descubrir la verdad sobre sus emociones, ni de revelarla. Por otra parte, los personajes de los que habla en Mes Apprentissages, pertenecen ahora al pasado, y la mayoría han muerto. Su primer marido, Willy, con quien comparte protagonismo en esta obra (él es su tema central), ha muerto hace cuatro años. Colette no teme pues ocasionar ningún daño moral con sus revelaciones y sí pretende, sin embargo, arreglar cuentas con su propio pasado y ante ella misma. Según esto, Mes Apprentissages se ajustaría a la convención liminar que afirman todas las autobiografías: la pretensión de sinceridad. En Mes Apprentissages, Colette diría la verdad, lo que hasta ahora había callado. De alguna manera así se afirma en el subtitulo por interposición de personaje:

Mes Apprentissages

Ce que Claudine n’a pas dit

Si Colette es Claudine, la primera y la tercera persona son un mismo personaje. Pero las máscaras han sido recurrentes en los textos de Colette. ¿No será Mes Apprentissages una nueva manera de esconderse, la definitiva "mise en abyme" del camuflaje? Porque Mes Apprentissages hablará del disimulo como del resultado de un entrenamiento, de un "aprendizaje" doloroso, de una lúcida vigilancia que adoptará a menudo formas de auto censura. En 1792, Mary Wollstonecraft publicó A Vindication of the Righ of Woman (Defensa de los derechos de la mujer). Hablaba allí de una sociedad que deforma a los seres de sexo femenino. Las mujeres, dice, a merced de sus sensaciones, condenadas a seducir para sobrevivir, han adquirido el hábito del engaño y del disimulo. Conceden más importancia a las apariencias que a la virtud verdadera. Sólo hay un modo de escapar a la trampa: declararse hombre (Barret-Ducrocq, 2000: 13).

Necesariamente, Colette se encuentra obligada a situarse con respecto a los estereotipos femeninos vigentes en su tiempo, a esos tipos de mujeres que todavía le deben mucho a la tradición romántica y a la moral burguesa. Su postura es muchas veces ambigua, ocupa una posición intermedia, entre la caricatura que provoca el rechazo y la representación disimulada de la tolerancia o de la aceptación. Y si Colette revela, quizás sólo lo hace para mejor ocultarse, para protegerse, "porque nada tranquiliza tanto como una máscara". A la creación de estas defensas contribuye la retórica y su talento de escritor: un principio dramático, una retórica del espectáculo envuelve y confunde los conceptos. Paréntesis y guiones, comentarios del texto, llamadas al lector, conclusiones osadas, máximas lapidarias, ponen en escena la lógica de una inteligencia alerta, y otras fórmulas, en la respiración musical del texto, se enfrentan a la tentación del lirismo sin rechazarla. Y así, la "sinceridad", esa convención autobiográfica, ese motivo obligado en el contrato de lectura, se convierte en un "placer simple" que rara vez se disfruta.

Aunque Colette pretendía rechazar las convenciones y describir sin engaño ni velo la novedad de sus sensaciones, las obras que preceden Mes Apprentissages en su bibliografía, ya pusieron a punto las estrategias de la ocultación:

El personaje de Léa, en Chéri, representa a la mujer que envejece y que ve cómo la relación que está viviendo y que se termina será posiblemente la última de su vida. Enamorada de un hombre mucho más joven que ella, ha querido creer durante un tiempo que aún era joven, o que la edad no tenía importancia. En realidad nunca lo pensó realmente; se esforzaba en ocultar y en ocultarse la realidad, en maquillar los signos del cansancio y del tiempo, en ofrecer una imagen que no era más que una pobre máscara imperfecta. Hasta aquí, el personaje de Léa es como el de cualquier otra mujer que envejece y no quiere verlo, más que triste o dramático, caricatural y patético. Pero con Léa, Colette anuncia un modelo de mujer que se propone alcanzar y que, ciertamente, parece que ella misma alcanzó: la mujer que disimula y que oculta su dolor, porque Colette desprecia sobre todo la emoción cuando se ofrece en espectáculo La lucidez de Léa cuando se mira en el espejo (otra máscara estereotipada), y es capaz de llamarse a sí misma "vieja" y "loca", es la lucidez que Colette contempla como una necesidad y como un destino, el que quisiera para ella. La inteligencia brilla cuando uno se convierte en el principal y privilegiado espectador de sí mismo. Escribir no es entonces más que una forma de crear un decorado, una imagen de seriedad o de lirismo; para los otros, la máscara del dolor (o su símbolo):

La belle main qui a laissé ici sa trace s'est détournée de toi à jamais

-Ce que je parle bien! Vous allez voir que le chagrin va me rendre poétique!

Elle se promena, s'assit, se recoucha, attendit le jour. Rose, à huit heures, la trouva

assise à son bureau et écrivant, spectacle qui inquiéta la vieille femme de chambre. (Colette, 1940: 96)

En Sido, la imitación de la madre se convierte en la mejor máscara. Todas las simpatías del lector se orientan hacía la madre de Colette. La escritora se ha encargado de elegir 
los mejores detalles, de perfeccionarlos, de ofrecer el retrato más atractivo, desde la mejor perspectiva, para preparar el camino de su propia justificación y de su propia alabanza. En la descripción de "Sido", las exageraciones son una máscara del lirismo, y contribuyen a convertir al personaje en un ser de excepción. Para construir su mito, Colette sólo tiene que imitar a la madre, adoptar su estilo; la publicidad, de la que ella se ha encargado, ya la precede: “Je répétais la fin de ses phrases. J'avais déjà la voix plus grave que la sienne, mais j'imitais sa manière. Je l'imite encore » (Colette, 1930: 53). El estilo de Colette, su fuerza de observación, la precisión de sus detalles, todos los lugares comunes que la crítica no cesará de repetir, ya estaban en las maneras de Sido, justificación y refugio de la joven Colette. Porque si Colette se enorgullece de parecerse a su madre, también sabe que posee características que podrían resultar extrañas o comprometedoras, sabe, sobre todo, que como ella está llena de contradicciones; decir que son un reflejo de la madre es una búsqueda de comprensión asegurada:

Il ne lui manquait pour être une provinciale type, que l'esprit de dénigrement. Le sens critique, en elle, se dressait vigoureux, versatile, chaud et gai comme un jeune lézard. Elle happait au vol le trait marquant, la tare, signalait d'un éclair les beautés obscures, et traversait, lumineuse, des cœurs étroits. (Colette, 1930 : 13)

El retrato que Colette ofrece de "Sido" está demasiado trabajado para que la intención sólo sea la recuperación de un tiempo, de una memoria o de un Paraíso. La descripción de "Sido" busca una posteridad en la imagen de la escritora. Y esta imagen deberá indudablemente favorecerla. La "buena hija" condescendiente y complaciente con las extravagancias de la madre, lo es primero con la imagen que quiere para ella. "Sido" es una transición cómoda, bella, y, sobre todo, útil. En La Chatte, abundan las sombras, los reflejos, la visión indirecta y parcial. Léa en Chéri se atrevía a mirar su imagen de vieja, y Colette a hacer de la vejez un monstruo que es necesario disfrazar:

Pouah! Adieu tout, c'est plus propre. Allons acheter des cartes à jouer, du bon vin, des marques de bridge, des aiguilles à tricoter, tous les bibelots qu'il faut pour boucher un grand trou, tout ce qu'il faut pour déguiser le monstre _ la vieille

boucher un grand trou, tout ce

En La Chatte, los espejos sirven también para que el otro vea la imagen que escapa al control. Alain puede ver en el espejo la mirada que Camila (su esposa) no ha tenido la precaución de disimular: “Dans le miroir, en face d'eux, il reçut le regard de Camille, noir de reproche, qui ne l'attendrit pas" (Colette, 1960: 17). Si en la educación social, en las buenas maneras y en la educación sentimental de las mujeres, el disimulo y el engaño ocupan un lugar central, si las mujeres han aprendido bien la lección y saben protegerse convenientemente, poco le queda al escritor por observar si no se convierte también en narrador omnisciente que lee y transcribe los más recónditos sentimientos.
Colette sigue experimentando con el artificio de la imagen que escapa al control, pero no a la responsabilidad del sujeto, y que por tanto revela aquello que éste más hubiera querido esconder: aquello que lo expone y lo hace vulnerable. En La Chatte, no son sólo los espejos, las sombras o los retratos, también los discursos tienen la virtud de convertirse en el reverso de imágenes reveladoras para el lector. Colette aplica a la novela el artificio de los "a parte" del teatro; ofrece sucesivamente la transcripción de lo que el personaje acaba de pronunciar y su discurso segundo, velado, recitado en silencio, a modo de ejercicio liberador; estas palabras paralelas y ocultas, Colette las ofrece al lector entrecomilladas (al mismo tiempo cuestión de deferencia y complicidad). Alain, que se entiende mejor y más directamente con su gata, Saha, que con su mujer utiliza el discurso paralelo para "decir" o "decirse" sin herir al otro: "Il trouvait un plaisir deshonnête, une commodité évasive à l'interpeller en lui-même. $<c^{\prime}$ est moins="'"

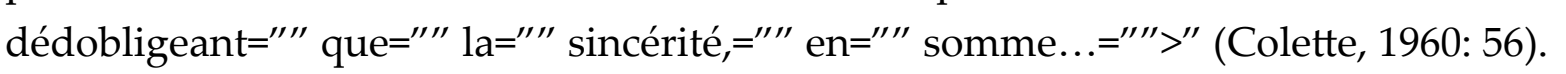

Puesto que la duplicidad se muestra, el lector puede entrever en ello algunos atisbos de sinceridad. Pero Colette sigue poniendo a punto sus estrategias. En la cita señalada se vislumbran la ambigüedad y el engaño. Aunque la narradora introduce una explicación que es confesión costosa, y califica ese "placer" de "deshonesto", lo considera "esa comodidad evasiva", las palabras doblemente encerradas en el texto, silenciadas pero pensadas por el personaje, son la formulación explícita del cinismo, una máscara de lujo. En los artículos de prensa Colette ha ensayado otros artificios. Uno de los más repetidos en este caso, y que tampoco está ausente de sus novelas, consiste en fingir la amargura pedagógica. Colette critica y aconseja, finge hacerlo con pasión, pero lo hace con amargura. Colette sabe aconsejar, pero quizás no es capaz de seguir sus propios consejos. En el artículo titulado "Visites", recogido en Quatre-Saisons (Inédits 1925), Colette pone el consejo en boca de una "sabia marquesa":

Déjà en ce temps vieux de vingt années, j'aurais voulu, imitant auprès de ces adolescents mal employés la sage marquise qui conseillait à son petit-fils : « Ne commets que les bêtises qui te font réellement plaisir », j'aurais voulu leur dire :

« N'accomplissez que les devoirs qui ont un sens ». (Colette, 1972b : 36)

Sólo se atreve a modificar, hipotéticamente, una máxima de autoridad establecida, detrás de la que tal vez esconda el hecho de que ella misma no se atreve a seguirla. Cuando años más tarde, Colette publica Mes Apprentissages, transposición literaria de una época de su vida, de los veinte a los treinta años, la época de su matrimonio con Wily, la distancia y un éxito ya conseguido y asegurado, le permiten juzgar severamente sus primeras obras. Lo que pudiera parecer una prueba de sinceridad dolorosa no es más que el cómodo privilegio de quien ya ha construido su mito. Oponerse a él, señalar sus fallos, en apariencia, no puede servir más que a alimentarlo. El motivo de la duplicidad, la temática de la simulación y de la mentira, las isotopías de la imitación 
y de la máscara son las claves de Mes Apprentissages. Atraídos por el título, los términos de la enseñanza, de la educación o del entrenamiento moral se diversifican y se contagian de cínica ironía. El término "dissimuler" explícita e implícitamente (Colette, 1972a: 38, 86, 149) contamina al sujeto y al objeto de esos hipotéticos "aprendizajes". El plural fragmenta y desprestigia la enseñanza, la convierte en adiestramiento, en mera "gymnastique sentimentale" (Colette, 1972b: 33); el resultado es algo práctico, una técnica a disposición, reutilizable en el momento adecuado, un reflejo. Y la moral que encierra carece de toda transcendencia, es concreta y útil, la cómoda moral de la fábula, esa que nos enseña a ser disciplinadas, a estar tranquilas y a vivir sin felicidad:

En Somme, j'apprenais à vivre. On apprend doncà vivre? Oui, si c'est sans bonheur. La béatitude n'enseigne rien. Vivre sans bonheur, et n'en point dépérir, voilà une occupation, presque une profession. (Colette, 1972a : 101)

Colette consigue borrar algunos estereotipos, trabajosamente, pero no consigue desprenderse de todos; la escritura le permitirá elegir aquellos que mejor le responda, los que le permitan vivir y los que mejor dibujen su leyenda. Es la autora de Claudine quien, treinta años más tarde, recuerda aquella época de entrenamiento, y la clarividente premonición de Catulle Mendès:

C'est vous, n'est pas, l'auteur des Claudine... Mais non, mais non, je ne vous pose pas de questions ; n'exagérez pas votre embarras...Dans...je ne sais pas moi... Dans vingt ans, trente ans, cela se saura. Alors vous verrez ce que c'est d'avoir, en littérature, créé un type. Vous ne vous rendez pas compte. Une force certainement Oh! Certainement! Mais aussi une sorte de châtiment, une faute qui vous suit qui vous colle à la peau, une récompense insupportable qu'on vomit... (Colette, 1972a : 55)

Los treinta años ya han transcurrido; todo el mundo sabe que es Colette, y no su marido Willy, la autora de Claudine. Es el buen momento para recordar lo que Mendès había profetizado; si alguien dudara aún de la autoría de sus primeras obras, Colette está alerta para señalar que ya en su momento se supo y que alguien con criterio literario lo consideró evidente desde un principio. La Colette, que aparentemente desvaloriza sus primeras obras, que las recuerda como un trabajo que le es impuesto y luego robado, no pierde, sin embargo, la ocasión de reivindicarlas una vez más. La autoridad de Mendès funciona como una estrategia que sella de nuevo la autenticidad de su obra. Nuevos detalles sobre la vida de la pareja y las actividades de Willy en aquella época, reaparecerán insistentemente para corroborarlo.

No cabe duda de que Willy es para Colette, además de su primer marido, un personaje interesante. Algunas fotografías de la época presentan a la pareja ante un escritorio. Colette añade a la imagen una leyenda irónica: “Colaboración”. El contraste entre la imagen de sumisión y tristeza que representa Colette y la explicación que propone el texto, puede entenderse, tras la lectura de Mes Apprentissages, como un principio de independencia y de rebeldía. Colette simula la colaboración y expone el disimulo, sumisa, pero dueña de su imagen; es consciente de la importancia social de la fotografía, "sensible à l'impact de la photographie sur la reconnaissance et la notoriété" (Maget, 2005: 63). La creación de un tipo comienza por la imagen; el mito es primero estereotipo, cómoda máscara. Igual que con la retórica da forma y sentido a sus textos, Colette manipula, retórica de la imagen, sus fotografías, consiguiendo imponer la imagen que quiere de sí misma (Maget, 2005: 64-65). La predicción de Catulle Mendès se habrá cumplido en todos los dominios: textos e imágenes han trabajado en la construcción del mito, al mismo tiempo recompensa y castigo. Esta es la dialéctica que Colette intenta reordenar y matizar, una vez más, en Mes Apprentissages. Aparentemente, el texto no responde a plan alguno; se trataría de una serie de recuerdos, de fragmentos que no tienen más relación que un común enunciador y su cronología. Colette quiere presentarlo así, sin una intención marcada, como algo que surge de manera espontánea y relativamente aleatoria. En esta dirección dirige la lectura y la interpretación de su texto, y para ello multiplica comentarios y referencias. Así se expresa, por ejemplo, cuando habla de los colaboradores ("los negros") de Wily: “Et je ne crois pas que je me laisse, au cours de ces pages sans ordre réfléchi, entraîner à dire pour quoi...j'ignore les noms des collaborateurs plus récents » (Colette, 1972a : 20).

Argumenta Colette una falta de reflexión y de orden en la construcción del texto, y sin embargo, señala la voluntad que mantiene firmes las riendas de su inteligencia y de su palabra. No, Colette no va a dejarse llevar hacia la confesión profusa y desordenada. La falta de orden es una pista falsa. La falta de reflexión, una estrategia para hacer pasar la confesión por auténtica y sincera. Colette juega con la contradicción y parece en algún momento dominarla, pero no deja de resultarnos extremadamente reveladora: para Colette no existe mayor amenaza que dejarse llevar, perder el control y el dominio sobre sí misma. Por necesaria que pueda resultar la confesión para su equilibrio o para su publicidad, Colette siempre intentará conservar una reserva. Si Colette con sus comentarios al texto pretende dirigir en su favor nuestra lectura, intentaremos leer entre las líneas y encontrar aquello que escapó a su control. No es fácil, sin embargo, en un texto que se defiende e impone una lectura, leer a Colette, al mismo tiempo con ella y contra ella, quizás retirando, momentáneamente, algunas de sus máscaras.

Mes Apprentisssages es un texto bien estructurado. El plural del título despista, propone fragmentación y cierto desorden..., pero no será ese el resultado. Quince fragmentos, o capítulos de dimensión irregular, entre los que la transición es siempre lógica, construyen la arquitectura del texto. Aunque los capítulos no cuentan con título 
ni están numerados, la disposición tipográfica los presenta claramente: cada nuevo capítulo se inicia en el centro de una nueva página.

El primer capítulo es el más largo, y si tenemos en cuenta que la relación con Willy será el centro temático de la obra, este primer capítulo contribuye a crear en el lector falsas expectativas: un ancho telón que se levanta sobre escenas inesperadas. Paradójicamente, la sorpresa es mínima.

La primera palabra del primer capítulo es la primera persona, y su primera frase, su primer enunciado, se cuela en el molde de una sintaxis negativa: para comenzar, lo que se afirma es un vacío:

\section{Je n'ai guère approché, pendant ma vie, de ces hommes que les autres hommes appellent grands. Ils ne m'ont pas recherchée. Pour ma part je les fuyais,... [...] Si leur présence manque à ces a Si leur présence manque à ces "sol'́né des êtest que je suis conpable de leur avoir - le sexe n'importe guère - préfére des êtres obscurs, pleins d'un suc qu'ils défendaient, qu'ils refusaient aux sollicitations banales (Colette, 1972a: 5).}

Las primeras líneas son una declaración de principios. Aparece la primera definición del texto, "souvenirs", y la negación sintáctica introduce un nuevo sistema de clasificación de los seres, la afirmación de una elección subjetiva y consciente, preferencia de la que, por falsa modestia (y para atraer simpatías), la autora se dice "culpable". En cualquier caso, es ella quien observa a estos "seres obscuros", ella quien elige los detalles y quien impone su visión: una serie de ejemplos nos llevarán a deducir cuáles son las características comunes de estos personajes, y porqué Colette los ha elegido: el primero es un joven. El detalle que lo destaca es que finge. Un joven que finge beber y que finge fumar opio. Colette interpreta la abstención real como un desafío, como un virtuosismo que sólo puede ser el fruto del ejercicio continuado y del control sobre sí mismo. El segundo personaje es una niña de ocho años. Una niña que se esconde, que finge que se pierde y que provoca conscientemente la angustia de su madre; la niña esto lo vive como un juego cruel que le produce placer, un juego del que ya no sabrá prescindir. Se lo confiesa a Colette, pues tampoco puede prescindir de la confesión, otro tipo de placer:

Je m'étonnai qu'elle jouât, par deux fois, son jeu devant moi. Elle ne me demandait aucune complicité ni promesse, semblait assurée de moi comme le furent, après elle, d'autres coupables, vaincus par la volupté de l'aveu et le besoin de mûrir sous un regard humain (Colette 1972a : 7-8)

El tercer personaje, es una mujer, Zaza. Colette la define con una fórmula que esconde el estereotipo: "le grenier d'abondance de l'homme". Se trata de la amante de un tal A (el nombre de los hombres es silenciado, sólo un signo matemático); al quien envidia un tal B. Colette cuenta la anécdota como una ecuación de resultado cierto, una parábola sencilla y trágica: $\mathrm{B}$, que envidia la suerte de A, pinta a la mujer con los trazos de la "mujer fatal". A le cuenta a la mujer cómo la describe B. La mujer adoptará para B la máscara de mujer fatal; tan bien representará su papel que B no tendrá más remedio que creer y sufrir la imagen que él mismo había inventado. Es la propia Zaza quien cuenta a la narradora la anécdota, y quien puntúa su discurso con abundantes puntos suspensivos. La conclusión es la muerte de B (crueldad que se cuenta sin ninguna emoción), y una sentencia: «Il ne faut pas tenter le diable, même par bêtise. Cet imbécile de B..., il a tenté le diable... » (Colette, 1972a : 10).

Tres ejemplos, y la paradoja es que de ello no se deriva conclusión alguna, ninguna influencia, ninguna enseñanza. En contraste con lo que parecía prometer el título, aparece una interpretación explícita: «Qu'il n'y ait pas eu, de mes ténébreux amis à moi, enseignement efficace d'une vertu ou d'un vice éclatants, osmose ni même simple contagion, je ne puis maintenant que m'en réjouir » (Colette, 1972a : 10). Sin embargo, nuestra lectura ya los ha asociado a Colette que nos los presenta, y ya hemos intuido qué pueden tener en común: una obsesión por camuflarse. Colette, tras haberlos dibujado, no escatima los esfuerzos para borrarlos. Afirma el deseo de ser "otro" y en la misma línea lo elimina:

Dans le temps de ma grande jeunesse, il m'est arrivé d'espérer que je deviendrais « quelqu'un ». Si j'avais eu le courage de formuler mon espoir tout entier, j'aurais dit « quelqu'un d'autre ». Mais j'y ai vite renoncé. (Colette, 1972a : 10-11)

Y sigue la lista de personajes, ahora con sus nombres y apellidos, cada vez más próximos a Colette, y deberíamos suponer que con mayor influencia en su vida. Colette nos desvía de esta suposición, reafirmándose en el carácter no pedagógico de sus encuentros. Este es el caso de Caroline Otero, a la que dedica un buen número de páginas: “- ainsi de la voix juste et majeure, par exemple de Mme. Caroline Otero, qui me transmit en pure perte, autrefois et sans obstination, de grandes vérités » (Colette, 1972a : 11). El contraste entre el grado de presencia y de importancia del personaje es sorprendente. La isotopia de "la enseñanza", una enseñanza en negativo, da coherencia al texto. La oposición utilidad/lujo la convierte en paradójica, en aprendizaje improbable: "Comme tout ce qui est luxe, elle dégage des enseignements divers" (Colette, 1972a: 12); Colette describe a Mme. Otero como un nuevo ejemplo de disfraz; el decorado de su vida y el motivo de la máscara contribuyen a definirla, los lugares comunes que etiquetan a la "mujer mayor". Apenas queda un paso para la definitiva cosificación de la mujer, una palabra: Mme. Otero es "une cariatide", y como ella todas las mujeres encorsetadas. Hablar de la decoración de sus casas, o de la moda que siguen religiosamente para seguir pareciendo jóvenes, las identifica y las confunde a todas, pues todas están deseosas de responder a un mismo estereotipo. Colette se distancia, exagera y caricaturiza: "par ce temps de grands corsets", la actriz 
Germaine Gallois, por ejemplo, no aceptará ningún papel que la obligue a aparecer sentada, la pobre mujer sólo recuperará la forma una vez la última función terminada y de vuelta a casa. Para Colette, describir el cuerpo aprisionado de la mujer supone esconder otras prisiones, convenciones no más ligeras.

Al final del párrafo, otro desmentido, hasta el punto de que, lectores atentos a sus trampas, podríamos concluir que dos negaciones seguidas constituyen una afirmación camuflada: Colette sí aprendió algo observando de cerca a todos estos personajes, estas escenas:

Spectacles dénués de sens et de profondeur, que nous chargeons de présage ; d'accent ; ils portent à jamais le chiffre d'une année, annoncent la fin d'une erreur, d'une prospérité. Partant aucun de nous ne pourrait jurer qu'il a peint, contemplé ou décrit en vain. (Colette, 1972a : 19)

Quizás no sea tanto como decir que el texto ha supuesto una nueva perspectiva y que ha aportado al recuerdo una transformación coherente, pero en cualquier caso, sea cual sea el sentido, éste no es ni gratuito ni indiferente. Quien iba a pensar, si la publicidad no precediera a la obra, que tras este desfile de personaje, entraría en escena, para ocuparla por completo, Willy, el primer marido de Colette (también, su primer amor). La relación con las escenas anteriores, en las que Colette sólo ha querido proponerse como perspicaz espectadora, se realiza mediante la partícula adversativa "mais", atraída naturalmente por el "Partant" de la frase que la ha precedido. Son demasiados cuidados, demasiadas precisiones, para que Colette se atreva a afirmar que su texto no es más que una serie de recuerdos desordenados. Su considerada sintaxis expresa su reserva y la protege. Para introducir a Willy en el texto empieza negando, restringiendo, acotando la escena:

Mais j'ai mal connu l'homme qui fit semblant, toute sa vie, d'être pauvre. Celui-là goûta des joies sans pareilles. Car, non seulement il dissimulait - ce qui est humain-

des biens inconnus, mais encore il empruntait aux pauvres. (Colette, 1972a : 19)

Como los personajes que lo han precedido, éste, que se convertirá en el protagonista del relato, se distingue también por su capacidad de disimulo y su virtuosismo en el fingimiento. Colette, que dice haberlo conocido mal, se arrogará, sin embargo, el poder de dibujarlo como una experta psicóloga, proponiendo siempre su interpretación como la buena y casi la definitiva. Es nombrado por primera vez en la página número 21: "Ceux qui ne l'ont presque pas connu l'appellent "le bon Willy". Ceux qui ont eu, d'un peu près, affaire à lui, se taisaient ». Entra en escena como fuente de anécdotas, pero va a resultar fundamental en la interpretación y la justificación que Colette inventa para su propia vida. Y es ahí donde comienza el siguiente capítulo, uno de los más importantes del libro. Se llega a él tras una mudanza y una elipsis narrativa. Nos encontramos "Rue
Jacob, au troisième étage,..."(Colette, 1972ạ: 25), en el desorden del apartamento de soltero de Willy. La descripción del espacio es una primera aproximación al personaje, un principio de fisionomía. Como su antítesis surge el recuerdo del orden de la infancia, el orden anterior al matrimonio. El matrimonio sólo le ha aportado a Colette enseñanzas negativas; durante algún tiempo conservó la esperanza en un retorno al Paraíso, creyó posible olvidarlas:

Je n'oublie pas le vivace et stupide espoir qui me soutenait: ce grand mal, la vie citadine, ne pouvait durer,... [...] par un choc qui me rendrait à la maison natale, au jardin, et abolirait tout ce que le mariage m'avait appris... (Colette, 1972a: 28-29)

Pero, de alguna manera, su disposición personal la había conducido a ese punto. Como el resto de las jóvenes de su tiempo, soñó con llegar a ser el capricho de un hombre maduro. Treinta años más tarde posee los instrumentos y la independencia necesaria para poder confesárselo a sí misma: “Elles sont nombreuses, les filles a peine núbiles qui rêvent d'être le spectacle, le jouet, le chef-d'oeuvre libertin d'un homme mûr [...] Je fus donc punie, largement et tôt" (Colette, 1972a: 29). ¿Qué aprendió Colette, el día que sorprendió a su marido con Charlotte Kinceler? El motivo, anecdótico en principio, podría no haber dado lugar más que a una escena de vaudeville, a la exageración, a los gritos o a las lágrimas. No ocurre así en el caso de Colette que, dueña de la situación, disimula: "Dehors, j'étais assez fière de n'avoir tremblé ni menacé" (Colette, 1972a: 30). Este es su principal aprendizaje de mujer, Colette llegará a dominarlo a la perfección, pues es una de las metas que se ha impuesto: Al principio no le resultó fácil, pero la animan sus progresos: cada vez consigue enmascarar mejor sus emociones. Este esfuerzo tiene al principio un honorable destinatario, Sido, la madre a la que quiere evitar el sufrimiento de la verdad. El programa de Colette es simple: conseguir engañarla, conseguir que su madre crea que ella es feliz. Y este empeño deberá perseguirlo durante trece años, los que duró su primer matrimonio. Poco importa que los demás no comprendan su posición ni sus actitudes, lo único que parece importarle es mantener a "Sido" en la ignorancia:

Il ne comprenait pas que signifient mon arrivée, mon mutisme, ma modération [...] il importait de tenir «Sido » dans l'ignorance. Je l'y tins. [...] mon rôle était difficile, surtout au commencement. (Colette, 1972a : 31)

Colette ofrece el ejemplo, iterativo, de una de sus visitas a «Sido ». En tres páginas, Colette resume y ofrece una solución a esta situación comprometida. Sido, sagaz observadora, le pregunta, la espía, la acorrala, pero Colette está bien entrenada. Como he señalado al principio, se parece a Sido, la imita, conoce sus estrategias: "Mais j'étais sa fille, et déjè savante au jeu" (Colette, 1972a: 32). Colette pone en juego todas sus estrategias, contar mil historias, no permitirse un solo gesto comprometedor (conservar 
su rostro de máscara), y sobre todo, vigilarse: "Je me surveillais durement", hasta el punto de creer y confiar en la posibilidad del control absoluto. Retener las lágrimas, privarse de llorar, esta abstención, ha constituido su entrenamiento a fondo y marcado su meta, de tal modo que es capaz de generalizar y de afirmar formalmente: "Mais on se vainc pourvu qu'on le veuille" (Colette, 1972ª̣: 33), fórmula que podría constituir su divisa.

El personaje de Charlotte Kinceler, otra mujer de artificios y máscaras, le sirve a Colette para introducir otro de sus motivos recurrentes, el de la rivalidad entre mujeres y la posibilidad de un arreglo de compromiso ("medirse" entre mujeres). En primer lugar, Charlotte Kinceler, la otra, será la primera en sorprenderse y en alabar su maestría: "Elle avoua à M. Willy l'estime que lui avait inspiré mon sang froid" (Colette, 1972a: 37). Colette confiesa que adquirió el hábito de escucharla y que aprendió mucho de ella:

\section{Cette jeune femme, qui eût une vie brève, m'apprit beaucoup. D'elle datent mes doutes sur l'homme à qui je m'étais fiée, intransigeant, beau, absurde ; d'elle me viennent l'idée de tolérance et de dissimulation, le consentement aux pactes avec une ennemie. (Colette, 1972a : 38)}

A esta síntesis lúcida, que justifica porqué Colette se ha detenido en este personaje siguen algunos detalles más concretos. Charlotte regentó una herboristería, a la que Colette acudía también en calidad de cliente. Allí tomó también ejemplo de su forma de tratar al público, "(elle) souriait d'un sourire comercial" (Colette, 1972a: 39). El fina de este momento lo marca la desaparición del personaje, su suicidio. La sobriedad del texto es en este caso sobrecogedora. Sólo unas líneas, sin concesión alguna al patetismo, casi un telegrama, sellan la muerte de Lotte, a los 26 años:

Par un après-midi de pluie d'été étouffante, elle passa dans son petit salon-arrièreboutique, et se tira un coup de revolver dans la bouche. Elle avait vingt-six ans, et des économies. (Colette, 1972a : 40)

Tras la pausa de la coma, la precisión que concluye: « et des économies », es la firma, el tic de estilo, de una irónica Colette, incapaz de privarse en el texto, de ese gusto agridulce que pone la guinda. En el capítulo siguiente regresan los recuerdos al principio del matrimonio, Colette tenía 21 años. Ahora es el momento de ofrecer una interpretación ajustada de los presagios que se escondían en las primeras contradicciones: "je conserve un souvenir net et fantastique", "symboles clairs et funestes" (Colette, 1972a: 41). Colette ya había hablado en otras ocasiones del régimen de trabajo que seguía durante su matrimonio. Hacía falta dinero, era la excusa, y Willy la obligaba a escribir, y a hacerlo sin descanso, dentro de un sistema casi carcelario, para luego vender los libros bajo su nombre. Colette insistirá de nuevo, treinta páginas más adelante, al marcar una fecha, el día en que Willy redescubre el cuaderno de Claudine à l'École, y que significó para ella un hito, irónico: “Et voilà comment je suis devenue écrivain" (Colette, 1972a: 70), pues se mantuvo fiel a su promesa de silencio. Como los otros "colaboradores" de Willy, sólo dió el espectáculo de su resignación. Si alguien pudo creer que esto era metafórico, o que Colette exageraba (lo que ciertamente ocurría), Colette, ahora, treinta años más tarde, vuelve a afirmarlo, y se apoya, incluso, en testigos prestigiosos (Catulle Mendès). Se reafirma y matiza. Todos los detalles, y las reflexiones que le evoca el recuerdo, obran en su favor. Colette se presenta, una vez más, como víctima que consiente en serlo y que se integra dentro de estereotipo de la relación romántica: señala así "les enchantements d'une prison volontaire", "l'obstination à vouloir souffrir par amour", "l'habitude de me taire". En motivo de la prisión, ambiguo, ("J'avais des compensations"), se completa con el de la enfermedad grave, que Colette sufrió realmente, que le devolvió a sido por un tiempo, y le trajo a casa amigos solícitos y protectores (Pierre Veber, Paul Masson, Marcel Schwob...). Hablar de ellos, y de otros jóvenes de la generación 1890-1895, los "plaisantins patents", no es una digresión, pues es también el motivo de la apariencia y la máscara el que los trae a escena (Colette, 1972ª: 48); la conexión de los temas sigue siendo clara y está asegurada. Una vez curada, Colette pasa revista al recuerdo de su estancia en Belle-Ile-en-Mer junto a Willy y a Paul Masson. Se trata de otra ocasión propicia al aprendizaje. Willy escribía una cantidad ingente de cartas, Colette tendría que haber sospechado algo, sin embargo, su voluntarioso entrenamiento está resultando efectivo: “Mais j’apprenais déjà à détourner les yeux..." (Colette, 1972a: 49).

En este clima de esfuerzo y disimulo, algunas descripciones de la vida al aire libre, algunos detalles humorísticos, contribuyen a relajar la escena. Pero siempre, esas anécdotas guardan alguna relación con el que ya podemos considerar el leitmotiv del texto. Así ocurre con la curiosa invención de Paul Masson, que realiza el catalogo de las obras "qui auraient dû être écrites", inventando sus títulos. ¿Por qué elige Colette contar esta anécdota?: sencillamente, porque le ha sorprendido, y comparando, puede apreciar en ella misma lo que su caso o su carácter tienen de insólito y de atractivo. Con cada personaje que se somete a su observación, Colette aprende algo: « Grâce à lui je cotai un peu plus haut ce que j'avais d'insolite, de désolé, de secret et d'attrayant » (Colette, 1972a: 51). De nuevo, el final del capítulo lo marca la muerte del personaje. Otro suicidio. El texto es sobrio, conciso, sin concesiones:

Il fit une fin classique d'homme facétieux: au bord du Rhin, il appliqua contre ses narines un tampon imbibé d'éther, jusqu'à perdre l'équilibre. Il tomba, et se noya narines un tampon imbibe dether, jusqu'
dans un pied d'eau. (Colette, 1972a: 52)

Como en el suicidio del que informó anteriormente, la última fórmula pone la nota pintoresca, la triste chispa de humor que brota en el contraste de lo absurdo y 
la amargura. En el capítulo siguiente, Colette evocará la vida bohemia, centrando su atención en "la vie bohème de Willy" y en las antiguas salas de redacción, en la "Brasserie Gambrinus", en "d'Harcourt", en "La Vachette", en el Barrio Latino. Entre esta "bohemia", Colette destaca por su opacidad y por su silencio, como las amigas de los jóvenes bohemios; una de ellas "qui se taisait avec forcé et opacité", muere de sífilis después de ocho días de hospital. No es un suicidio, pero de nuevo una muerte cierra un momento en los recuerdos, agridulce y paradójico: "un malaise bien agréable" (Colette, 1972a: 58). El momento siguiente sólo ocupa tres páginas. Se encadena al anterior como un anexo: nuevas precisiones sobre la vida bohemia. Capítulo de transición en el que el tiempo corre más rápido. Colette tiene ya 24 años, conoce a Louis Forest, monta en bicicleta....; una vida tranquila que no merece la pena traer al texto: "Évoquerai-je quelques dimanches de canotage sur la Marne et la Seine? Ils ne valent pas la peine..." (Colette, 1972a: 61-62). La renuncia da paso a otros recuerdos, a otro momento; ya estamos en los años 1986-1987; un balanceo de estaciones: “Mois d'hiver, mois d'été..." (Colette, 1972a: 64) introduce la constante de su vida, repetición, resignación, y la imposibilidad de gozar de un placer simple; tan habituada está ya Colette a retenerse y a refugiarse en sus máscaras:

Et je fus longue à briser la contrainte qui me retenait non pas d'aimer ceux qui me faisaient accueil, mais de m'abandonner au plaisir simple de me montrer telle que j'étais . (Colette, 1972a : 65)

Una transición que recuerda el comienzo del texto, y Willy es otra vez su centro de atención. Primero un retrato físico, luego el análisis de la relación y la reflexión sobre el miedo que le inspira. Colette parte de su caso y rápidamente generaliza y amplía la experiencia; se ayuda de comparaciones. Para pintarse "víctima" se compara con un estereotipo, "un enfant-martyre", o encuentra en los animales la imagen evidente que representa su caso: "Peut-être la souris a-t-elle le loisir de trouver qu'entre deux blessures la patte du chat est douce" (Colette, 1972a: 67). Más adelante vuelve a señalar de modo aún más explícito quién es el ratón y quién el gato: “il n’omit jamais de ménager ma part de tourments précis et de plaisirs confus" (Colette, 1972a: 85). En cualquier caso, Willy conservará "l'amer prestige du pédagogue" (Colette, 1972a: 93). Colette maneja una doble retórica, la forma concreta y la forma abstracta de mostrar lo que a los ojos de Mary Wollstonecraft es precisamente la causa de la inferioridad social de las mujeres.

Une éducation fautive les habitue des l'enfance, à forger leurs chaînes et à accepter pour naturel un ordre qui n'est que le produit de leur conditionnement. Ce même conditionnement fait de la majorité d'ente-elles des infirmes de la raison. Leur ignorance réduit leur intérêt pour le monde à des sujets frivoles. Elles sont vouées au plaisir, à la merci de leurs sensations... (Barret-Ducrocq, 2000: 13-14)

Colette cuenta en Mes Apprentissages el desafío que ha mantenido con ella misma. Aunque no fue feliz, supo gozar del "decorado" de su vida, de un "confort de scribe" (Colette, 1972a: 78), una buena mesa y una buena lámpara; aprendió el coraje en el trabajo, la voluntad y la constancia; aprendió sobre todo a desconfiar de la emoción y a camuflarla, a pulirla, a controlarla, toda una retórica del texto. Willy la apodó "la dernière des lyriques", quizás, la última mujer que de una manera natural respondía a la estética del romanticismo. Colette se vigiló más desde entonces, y trabajó para despegarse de ese tópico. Intentó dejar atrás, aparentemente, el papel de víctima, aunque no dejó por ello de recordarlo y de justificarlo:

“Ces détails de captivité quotidienne ne sont pas à mon honneur, j'en conviens, et je n'aime pas faire figure de brebis [...] l'art domestique de savoir attendre, dissimuler, de ramasser des miettes, reconstruire, recoller, redorer, changer en mieux-aller le pis-aller, perdre et regagner dans le même instant le goût frivole de vivre...J'ai appris surtout à réussir entre quatre murs presque toutes les évasions, à transiger, acheter, ..." (Colette, 1972ª : 86).

Anticipándose a los comentarios y a las posibles críticas perspicaces, Colette sólo se desprestigia en apariencia; el análisis lúcido de los detalles le otorgará un prestigio renovado y más seguro. La interpretación de su actitud puede convenir también a su retórica: También en su texto disimula, y recoge restos y reconstruye y ordena a su manera, y pierde, pero sobre todo gana la estima de su público. Y a Willy, para quien ella fue rentable, lo convierte ahora en objeto de su propiedad, en su personaje de primer plano, en el protagonista de una serie de aventuras que bien podrían calificarse de picarescas: "Mon héros, contrebandier de la petite Histoire littéraire, je le trouve d'une taille et d'une essence à inspirer, et à supporter la curiosité" (Colette, 1972: 90)

Al final de Mes Apprentissages Colette ha alcanzado la treintena, si se compara con Polaire, ella ya tiene "plus de dix ans d'école" (Colette, 1972å: 116), sabe callar y disimular, y sin embargo, ha soñado tantas veces con escapar, a esperado tanto, que no será ella quien diga la última palabra sino Willy:

Rien ne presse...? J'entends: “Tout est fini" C'est moi qui aurais voulu dire "tout est fini". Puisque je ne l'ai pas dit, je n'ai plus qu'à me taire $[. .$.$] « j'attends une fin »,$ en sachant que ce n'est pas moi qui mettrai terme à ma pleutrerie, mais l'homme qui le premier disposa de moi. Et toujours cette modération, ce peu de bruit...Un silence comme par temps de neige. (Colette, 1972a : 156)

Como Alain en La Chatte, Colette se construye en la escucha su discurso paralelo. El final del texto se abre a la hipótesis, instala otra máscara, otra vuelta de tuerca, la transformación siempre posible del texto: 
Si j'écrivais quelque jour mes souvenirs de "l'autre versant", il me semble que par contraste le "han" d'effort, le cri de douleur y rendraient un son de fête, et je ne saurais m'y plaindre qu'avec un visage heureux. (Colette, 1972a : 157)

Ahora sí, Colette se nos escapa de nuevo. Su imagen ocupa ya el otro lado del espejo.

\section{REFERENCIAS BIBLIOGRÁFICAS}

Barret-Ducrocq, F., "Un sexe peut-il en cacher un autre? ", De la différence des sexes entre les femmes, Paris, P.U.F, 2000, pp. 9-25.

Bonal, R y Remy-Bieth, M., Colette intime, Paris, Phébus, 2004.

Colette, Sido, Paris, Ferenczi, 1930.

----, Chéri, Paris, Fayard, 1940.

----, La Chatte, Paris, Hachette, 1960.

----, Mes Apprentissages, Paris, Hachette, 1972a.

----, Le Voyage égoïste, Quatre-saisons, Paris, Hachette, 1972b.

----, Lettres à ses paires, Paris, Flammarion, 1973.

Ducrey, G., "Colette et la photographie », Notre Colette, Rennes, Presses Universitaires de rennes, 2004, pp. 91-105.

Kristeva, J., Le Génie féminin, T. II : Colette ou la chair du monde, Paris, Fayard, 2002.

Le Hardouin, M., Colette, Paris, Éditions Universitaires, 1956.

Maget, F., «Un cas exemplaire de manipulation de l'image par Colette : Mes Apprentissages », Cahiers Colette, no 27, 2005, pp. 63-82.

Reymond, E., Le rire de Colette, Paris, A. G. Nizet, 1988.

Tegyey, G., Analyse structurale du récit de Colette, Debrecen, Kossuth Lajos Tudományegyetem, 1988. 